\title{
Cross-Coupling Reaction of 2-halo1-methyl-1H-imidazo[4,5-b]pyridine Offers a New Synthetic Route to Mutagenic Heterocyclic Amine-PHIP and DMIP
}

\author{
Ayyiliath M. Sajith ${ }^{\dagger * *}$, Arayambath Muralidharan ${ }^{\dagger, * *}$, Ranjith P. Karuvalam ${ }^{\S}$, and Karickal R. Haridas ${ }^{\S}$ \\ 'Organic Chemistry Division, School of Chemical Sciences, Kasargod Govt. College, Kannur University, Kasargod, India. \\ ${ }^{*}$ E-mail: sajithmeleveetil@gmail.com \\ "Organic Chemistry Division, School of Chemical Sciences, Nehru Arts and Science College, Kannur University, Kannur, India \\ ${ }^{*}$ E-mail: drmuralinasc@yahoo.com \\ ${ }^{\S}$ Organic Chemistry Division, School of Chemical Sciences, Kannur University Payannur Campus, India
}

(Received November 27, 2012; Accepted April 9, 2013)

\begin{abstract}
A modified synthetic approach to the synthesis of heterocyclic food mutagens, 2-amino-1-methyl-6-phenylimidazo[4,5-b]pyridine (PHIP) and 2-amino-1,6-dimethylimidazo[4,5-b]pyridine (DMIP) is reported. This route highlights an optimized palladium catalysed Buchwald cross-coupling of 2-halo-1-methyl-imidazo[4,5-b]pyridine with benzophenoneimine followed by acidic hydrolysis to yield compound 7. Using finely tailored conditions, Suzuki cross-coupling reactions with highly efficient catalytic systems were performed as the final step on $\mathbf{8}$ to introduce the aryl group and methyl group on the heterocyclic core.
\end{abstract}

Key words: Buchwald coupling, Imidazopyridine, Suzuki coupling, Heterocyclic amines

\section{INTRODUCTION}

Imidazo pyridine derived structures are an important class of heterocycles that have been widely studied for biological activity. ${ }^{1}$ They can be considered as structural analogs of purines and are of potential medicinal relevance. $^{2}$ These data stimulated our studies towards synthesis and medicinal chemistry applications ${ }^{3-5}$ of this heterocyclic core. $^{6-9}$

A series of mutagenic and carcinogenic heterocyclic amines has been identified from cooked meat and fish. Most abundant of these heterocyclic amine is 2-amino-1methyl-6-phenyl imidazo[4,5-b]pyridine ${ }^{10}$ and 2-amino1,6-dimethylimidazo[4,5-b]pyridine. These amines are believed to form covalent DNA adducts ${ }^{11}$ resulting in genetic mutations in animal and human models and is suspected to be responsible for various types of cancer such as prostate, breast and colon on humans. Hence, chemical standards of these mutagens needs to be made for biological assays to assess the risk associated with their consumption.

Nowadays, microwave assisted organic synthesis (MAOS) ${ }^{12}$ plays a key role in drug development. One of the most widely studied reactions in microwave reactors is Palladium- catalysed reactions which usually takes hours and days to for completion. Rapid lead generation and optimization has recently been facilitated by the emergence of $\mathrm{MAOS}^{12}$ and the technique is today one of the major tool for the medicinal chemist. MAOS can facilitate the discov- ery of new reactions and reduce cycle time in optimization of reactions. In addition, it serves to expand the chemical space in compound library synthesis.

\section{RESULTS AND DISCUSSION}

As a part of our ongoing research on Imidazo[4,5b]pyridine based structures, ${ }^{8}$ we were interested in developing an expedient and flexible synthesis of PHIP and DMIP, that would be useful in making isotope labelled and metabolites of 9 and 10. Different approaches for the synthesis of these potential food mutagens are available in literature. ${ }^{13-16}$ In this paper we report an alternative approach to the synthesis of these amines. Our method relies upon the synthesis of 2-halo-1-methyl-imidazo[4,5-b]pyridine derivative, $\mathbf{6}$ as outlined in Scheme 1, which provides an easy handle for incorporating various functionalities at the second position of this heterocyclic core. This halo intermediate was efficiently synthesized starting from 3-amino-2nitro pyridine. The first step involves the diazotisation reaction of 1 to yield the fluoro intermediate in $65 \%$ yield, which was displaced by methyl amine in THF at RT to get compound 3. Compound 3 was reduced by $\mathrm{Fe} / \mathrm{AcOH}$ to yield the diamine derivative which was treated with formic acid and trimethylorthoformate to access the Imidazo[4,5b]pyridine core 5 .

Metallation reactions of $\mathbf{5}$ with different bases (n-BuLi, $\mathrm{t}$-BuLi, LDA) were explored to find an optimum condi- 

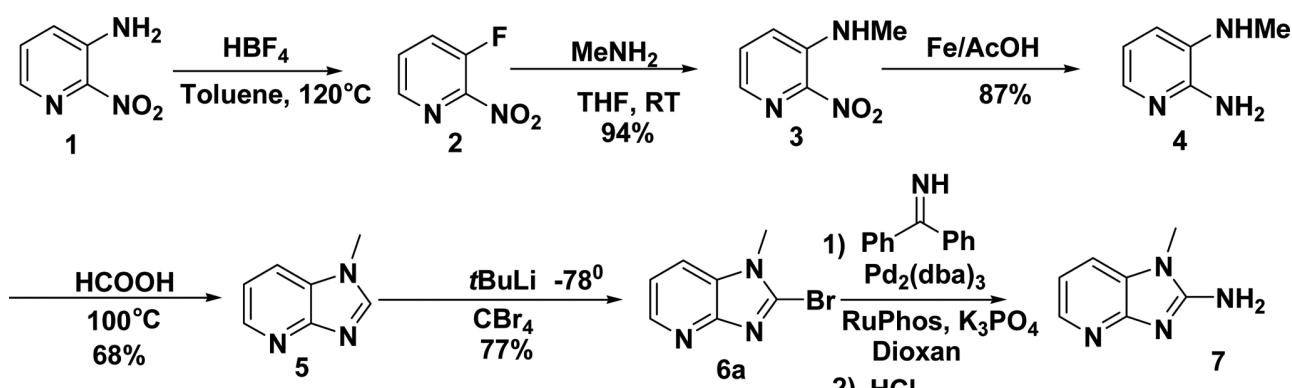<smiles>Cn1cnc2ncccc21</smiles>

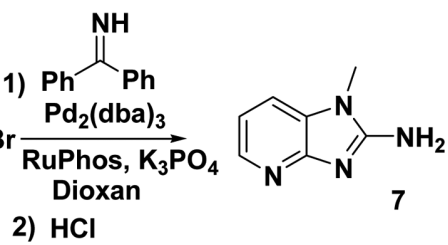<smiles>Cn1c(N)nc2ncc(Br)cc21</smiles>

Scheme 1. Synthesis of Bromo intermediate.

tion for the synthesis of the halo intermediate 6 . The chloro intermediate was synthesized according to the procedure mentioned in reference 8 . Tertiary butyl lithium was found to be a better choice of base to yield compound $\mathbf{6}$ in high yields. With $\mathrm{n}-\mathrm{BuLi}$ we observed n-Butylated product as a competing side product along with the required product. Once the halo intermediate $\mathbf{6}$ is synthesized, it could be used as an effective handle for preparing novel analogs based on the core structure which can lead to much more diverse molecules which are prone to have potential biological importance.

The use of benzophenone imine as nucleophilic crosscoupling partner ${ }^{17}$ in the Buchwald cross-coupling reactions aryl/heteroaryl halides with subsequent hydrolysis of the resultant imine permits the conversion of aryl/heteroaryl halides to their corresponding amine derivatives. Though many other ammonia equivalents ${ }^{18,19}$ have been used to attain this goal, however, benzophenone imine remains the widely employed reagent in the presence of range of functional groups, with aryl/heteroaryl halides. In this paper we report the use of benzophenoneimine as the masking amine source for the synthesis of potential food mutagens PHIP and DMIP.

Palladium catalysed Buchwald cross-coupling reactions were employed on the halo intermediate, (6a, and 6b) with benzophenoneimine followed by treating the crude reaction mixture in THF with $\mathrm{HCl}$ to get compound 7. Different palladium catalysts and ligands combinations were tried on this system to find an appropriate catalyst that would enhance the coupling (Table 1). Table 2 shows the different bases that were explored in order to find an effective base that would enhance the coupling yield. From the table it is clear that $\mathrm{K}_{3} \mathrm{PO}_{4}$ was found to be an effective base among all the bases explored. Surprisingly, $\operatorname{Pd}_{2}\left(\mathrm{dba}_{3} /\right.$
Table 1. Effect of catalyst on the Buchwald coupling ${ }^{\mathrm{a}}$ of $6 \mathbf{a}$ and $\mathbf{6 b}$ with benzophenoneimine

\begin{tabular}{ccc}
\hline Entry & Catalyst/Ligand & \%Yield of $7^{\mathrm{b}}$ \\
\hline 1 & $\mathrm{Pd}_{2}(\mathrm{dba})_{3} / \mathrm{PPh}_{3}$ & Traces \\
2 & $\mathrm{Pd}_{2}(\mathrm{dba})_{3} /$ Xanthphos & Traces \\
3 & $\mathrm{Pd}_{2}(\mathrm{dba})_{3} /$ X-Phos & 25 \\
4 & $\mathrm{Pd}_{2}(\mathrm{dba})_{3} / \mathrm{S}-$ Phos & $45(35)^{\mathrm{c}}$ \\
5 & $\mathrm{Pd}_{2}(\mathrm{dba})_{3} /$ RuPhos & $60(52)^{\mathrm{c}}$ \\
\hline
\end{tabular}

${ }^{\mathrm{a}}$ Reaction conditions: 6a $(0.5 \mathrm{mmol})$, benzophenoneimine $(0.9 \mathrm{mmol})$, $\mathrm{K}_{3} \mathrm{PO}_{4}$ (3 mmol), Pd catalyst (5 mol \%), Ligand (10 mol \%), Dioxan, $120^{\circ} \mathrm{C}$ microwave. After completion of the reaction as indicated by $\mathrm{TLC}, \mathrm{HCl}$ was added to the reaction mixture and stirred at RT overnight. ${ }^{b}$ Yields correspond to isolated yields of 7. ${ }^{\mathrm{c}} 6 \mathrm{~b}$ was used as the halo intermediate instead of 6 a.

Table 2. Effect of base on the Buchwald coupling ${ }^{\mathrm{a}}$ of $\mathbf{6 a}$ and $\mathbf{6 b}$ with benzophenoneimine

\begin{tabular}{ccc}
\hline Entry & Base & \%Yield of $7^{\mathrm{b}}$ \\
\hline 1 & $\mathrm{KOAc}$ & Traces \\
2 & $\mathrm{Na}_{2} \mathrm{CO}_{3}$ & Traces \\
3 & $\mathrm{~K}_{2} \mathrm{CO}_{3}$ & 25 \\
4 & $\mathrm{~K}_{3} \mathrm{PO}_{4}$ & $42(35)^{\mathrm{c}}$ \\
5 & $\mathrm{~K}_{3} \mathrm{PO}_{4}$ & $65(55)^{\mathrm{c}}$ \\
\hline
\end{tabular}

${ }^{\mathrm{a}}$ Reaction conditions: $6(0.5 \mathrm{mmol})$, benzophenoneimine $(0.9$ $\mathrm{mmol}), \mathrm{K}_{3} \mathrm{PO}_{4}(3 \mathrm{mmol}), \mathrm{Pd}_{2}(\mathrm{dba})_{3}$ catalyst (5 mol \%), RuPhos $(10 \mathrm{~mol} \%)$, Dioxan, $120^{\circ} \mathrm{C}$ microwave. After completion of the reaction as indicated by $\mathrm{TLC}, \mathrm{HCl}$ was added to the reaction mixture and stirred at RT overnight. ${ }^{\text {b}}$ Yields correspond to isolated yields of 7. ${ }^{\mathrm{c}} 6 \mathrm{~b}$ was used as the halo intermediate instead of $6 \mathrm{a}$.

RuPhos was found to give better conversions to product compared to other catalytic systems. A major problem encountered during this coupling reaction was the dehalogenation. It has been shown that increasing the catalytic activity of the palladium catalyst employed by using ligands which are sterically demanding and electronically rich, 


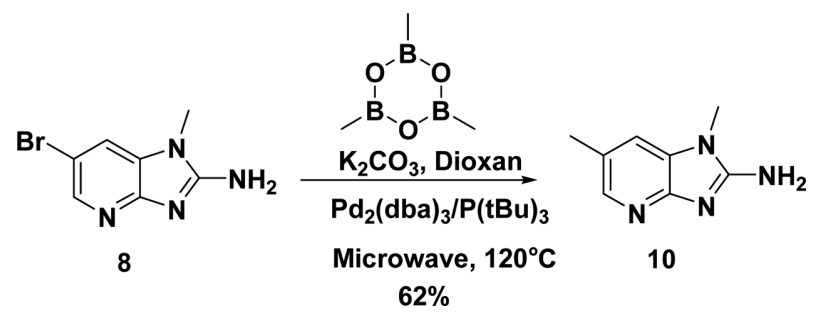

Scheme 2. Synthesis of DMIP.<smiles>Cn1c(N)nc2ncc(-c3ccccc3)cc21</smiles>

Scheme 3. Synthesis of PHIP.

facilitates the coupling. Thus using $\mathrm{Pd}_{2}(\mathrm{dba})_{3} / \mathrm{Ru}-\mathrm{Phos}$ combination we could get $50 \%$ yield over two steps to yield the compound 7 . Both the halo intermediates $(\mathrm{Br}, \mathrm{Cl})$ were found to be effective under Buchwald conditions and yielded the amine intermediate in reasonable yields, Table 1 . The use of the weak base $\mathrm{K}_{3} \mathrm{PO}_{4}$ provides excellent functional group tolerance and was found to be superior in enhancing the yield. Bromination of 7 using Bromine/AcOH yielded the compound $\mathbf{8}$ in excellent yields. Finally, Suzuki coupling was employed on compound 8 to access the title compounds PHIP and DMIP. In the synthesis of DMIP, Scheme 3, we found that adding water to the reaction mixture as employed for the synthesis of PHIP, Scheme 2, yielded less product formation and hence non-aqueous conditions were employed for Suzuki coupling. Under these finely tailored conditions, Trimethyl boroxine was found to be more

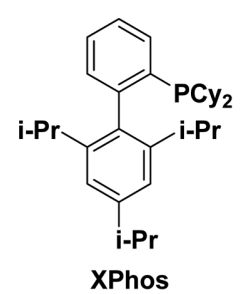<smiles>COc1ccccc1-c1c(OC)cccc1OC</smiles>

SPhos

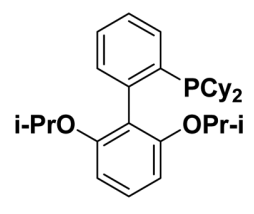

RuPhos<smiles>[Y20]C1([14CH3])c2cccc(P)c2Oc2c(P)cccc21</smiles><smiles>c1ccc(P(c2ccccc2)c2ccccc2)cc1</smiles>

Triphenylphosphine

Scheme 4. Structures of the ligands used for screening the Buchwald reaction.

Table 3. Effect of base on the Suzuki coupling ${ }^{\mathrm{a}}$ of $\mathbf{8}$ with Trimethyl boroxine

\begin{tabular}{ccc}
\hline Entry & Base & \%Yield of $10^{\mathrm{b}}$ \\
\hline 1 & $\mathrm{KOAc}$ & $\mathrm{NR}$ \\
2 & $\mathrm{Na}_{2} \mathrm{CO}_{3}$ & $\mathrm{NR}$ \\
3 & $\mathrm{~K}_{2} \mathrm{CO}_{3}$ & 57 \\
4 & $\mathrm{Cs}_{2} \mathrm{CO}_{3}$ & 62 \\
\hline
\end{tabular}

${ }^{\mathrm{a}}$ Reaction conditions: 8 (1 equiv), Trimethyl boroxine (1.3 equiv), Base (3 equiv), $\mathrm{Pd}_{2}(\mathrm{dba})_{3}$ catalyst $(5 \mathrm{~mol} \%), \mathrm{P}(\mathrm{tBu})_{3}(10 \mathrm{~mol} \%)$, Dioxan, $120^{\circ} \mathrm{C}$ microwave.

Table 4. Effect of catalytic system on the Suzuki coupling ${ }^{\mathrm{a}}$ of $\mathbf{8}$ with Trimethyl boroxine

\begin{tabular}{ccc}
\hline Entry & Catalyst & \%Yield of $10^{\mathrm{b}}$ \\
\hline 1 & $\mathrm{Pd}_{2}(\mathrm{dba})_{3}$ & $\mathrm{NR}$ \\
2 & $\mathrm{Pd}_{2}(\mathrm{dba})_{3} / \mathrm{PPh}_{3}$ & 25 \\
3 & $\mathrm{Pd}_{2}(\mathrm{dba})_{3} / \mathrm{PCy}_{3}$ & 57 \\
4 & $\mathrm{Pd}_{2}(\mathrm{dba})_{3} / \mathrm{P}(\mathrm{tBu})_{3}$ & 54 \\
\hline
\end{tabular}

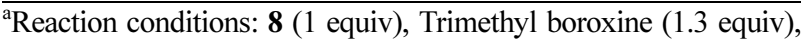
Base (3 equiv), $\mathrm{Pd}_{2}(\mathrm{dba})_{3}$ catalyst (5 mol \%), Ligand (10 mol \%), Dioxan, $120{ }^{\circ} \mathrm{C}$ microwave.

effective cross-coupling reagent compared to methyl boronic acid. Incomplete conversions and use of excess methyl boronic acids to drive the reactions to reasonable conversions were required when compared to trimethylboroxine. The use of trimethylboroxine in this cross-coupling reaction was instrumental in the synthesis of DMIP. Table 3 shows the effect of base in the Suzuki coupling reaction of 8 with Trimethyl boroxine. The use of highly efficient catalytic systems was required due to the possibility of catalyst deactivation that can be encountered while using hetero aromatic substrates as the cross-coupling partners, Table 4. Both $\mathrm{P}(\mathrm{tBu})_{3}$ and $\mathrm{PCy}_{3}$ were found to be effective ligands along with $\operatorname{Pd}_{2}(\mathrm{dba})_{3}$ for the Suzuki cross-coupling reactions of 8 with trimethylboroxine. The use of S-Phos as a choice of ligand under aqueous conditions was required for better conversions of Suzuki coupled product, as the reaction under non aqueous conditions using phenyl boronic acid showed only traces of product formation. Since compounds 9 and $\mathbf{1 0}$ are known mutagens and suspected carcinogens, direct contact should be avoided.

The efficiency with which the catalytically active, monoligated $\operatorname{Pd}(0)$ complex is formed before entering the catalytic cycle is the deciding factor in the selection of reaction protocol for palladium catalyzed amination reactions. If a $\mathrm{Pd}(\mathrm{II})$ salt such as $\mathrm{Pd}(\mathrm{OAC})_{2}$ is used, reduction of $\mathrm{Pd}(\mathrm{II})$ to $\mathrm{Pd}(0)$ must occur before the cross-coupling reaction can take place. The need for reduction step to form $\operatorname{Pd}(0)$ can be avoided by using a stable $\mathrm{Pd}(0)$ complex as the $\mathrm{Pd}$ source. In many 
cases, $\mathrm{Pd}_{2}(\mathrm{dba})_{3}$ was found to be suitable and effective palladium source in conjunction with dialkylbiaryl phosphines for Buchwald cross-coupling reactions and in our Buchwald reaction protocol we can see that $\mathrm{Pd}_{2}(\mathrm{dba})_{3}$ along with RuPhos followed by acid hydrolysis provided better conversions to 7 (Table 1). The most important advantages of this route to access these title compounds are safer reaction conditions compared to the other routes employed in the previous literature. Moreover, the conversion of 5 to 7 required higher temperatures and pressures in bomb calorimeter in previously reported methods. Here we employ a much safer and environmentally friendly method to access compound 7 .

\section{CONCLUSION}

We have reported a new route to the synthesis of potential food mutagen, PHIP and DMIP (compounds 9 and 10). This route involves metallation reaction on 5 to yield compound 6, which can be used as efficient intermediate for further derivatzation to yield novel analogs. Also optimised palladium catalysed Buchwald cross-coupling reaction was employed in this synthetic route which can be useful in synthesizing novel $\mathrm{N}$-arylated Imidazo[4,5-b]pyridines.

Acknowledgments. The authors are thankful to organic chemistry division, School of Chemical Science department, Kannur University and the Head of chemistry department, Professor Gopalan, Govt. College Kasargod for providing facilities and good support for research work. And the publication cost of this paper was supported by the Korean Chemical Society.

\section{REFERENCES}

1. Aridoss, G.; Balasubramaniam, S.; Parthiban, P.; Kabilan, S. Eur. J. Med. Chem. 2006, 41, 268 and references therein.
2. Youssef, A. F.; E1-Gendy, M. A.; Aboutaleb, N. A. E.; Ahmed, S. H. Egypt. J. Pharm. Sci. 1982, 23, 131.

3. Cristalli, G.; Vittori, S.; Eleuteri, A.; Volpini, R.; Vamaioni, E.; Lupidi, G.; Mohmoud, N.; Bevilacqua, F.; Palu, G. $J$. Med. Chem. 1995, 38, 4019.

4. Temple, C.; Rose, J. D.; Combu, R. N.; Rener, G. A. J. Med. Chem. 1987, 30, 1746.

5. Temple, C. J. Med. Chem. 1990, 33, 656.

6. Bukowski, L.; Janowiec, M. Pharmazie 1989, 44, 267.

7. Itoh, T.; Mase, T. Tetrahedron Lett. 2005, 46, 3573.

8. Sajith, A. M.; Muralidharan, A. Tetrahedron Lett. 2012, 53, 1036.

9. Doucet, H.; Hierso, J. Angew. Chem., Int. Ed. 2007, 46, 834.

10. Felton, J. S.; Knize, M. G.; Shen, N. H.; Lewis, I. R.; Anderson, B. D.; Happe, J.; Hatch, F. T. Carcinogenesis 1986, 7, 1081.

11. Buonarati, N. H.; Tucker, J. V.; Minkler, J. L.; Wu, R. W.; Thompson, L. H.; Felton, J. S. Mutagenesis 1991, 6, 253259.

12. Some recent reactions facilitated by microwave irradiations. Synthesis of heterocycles: Triazoles: (a) Bentiss, F.; Lagrenee, M.; Barby, D. Tetrahedron Lett. 2000, 41, 1539. Thiazoquinazolines: (b) Besson, T.; Guil-lard, J.; Rees, C. W. Tetrahedron Lett. 2000, 41, 1027. Quinolines: (c) Ranu, B. C.; Hajra, A.; Jana, U. C. Tetrahedron Lett. 2000, 41, 5891.

13. Knize, M. G.; Felton, J. S. Heterocycles 1986, 24, 18151819.

14. Fabio, S. B.; Tullio, C. Tetrahedron Lett. 1997, 38, 77937796.

15. Christopher, J. C.; James, E. B.; Mary, J. T. ARKIVOC 2002, 90-96.

16. Tominari, C.; Akiko, T.; Haruyuki, Y.; Kenichi, H.; Eiichi, S.; SatoshI, H. J. Org. Chem. 1993, 58, 7952-7954.

17. Wolfe, J. P.; Ahman, J.; Sadighi, J. P.; Singer, R. A.; Buchwald, S. L. Tetrahedron Lett. 1997, 38, 6367-6370.

18. Lee, S.; Jorgensen, M.; Hartwig, J. F. Org. Lett. 2001, 3, 2729-2732.

19. Huang, X. H.; Buchwald, S. L. Org. Lett. 2001, 3, 34173419. 